\title{
Obstructive sleep apnea: management considerations in psychiatric patients
}

\author{
This article was published in the following Dove Press journal: \\ Neuropsychiatric Disease and Treatment \\ 15 October 2015 \\ Number of times this article has been viewed
}

\author{
Taryn Heck' \\ Monica Zolezzi² \\ 'Pharmacy Department, University \\ of Alberta Hospital, Alberta Health \\ Services, Edmonton, $A B$, Canada; \\ ${ }^{2}$ Clinical Pharmacy and Practice, \\ College of Pharmacy, Qatar University, \\ Doha, Qatar
}

\begin{abstract}
Psychiatric disorders and obstructive sleep apnea (OSA) are often comorbid. However, there is limited information on the impact of psychotropic medications on OSA symptoms, on how to manage psychiatric pharmacotherapy in patients presenting with OSA, or on the effectiveness and challenges of OSA treatments in patients with comorbid mental illness. As such, the objective of this article is to provide an overview of some epidemiological aspects of OSA and treatment considerations in the management of OSA in individuals with comorbid psychiatric disorders. Predefined keywords were used to search for relevant literature in electronic databases. Data show that OSA is particularly prevalent in patients with psychiatric disorders. The medical care that patients with these comorbidities require can be challenging, as some of the psychiatric medications used by these patients may exacerbate OSA symptoms. As such, continuous positive airway pressure continues to be the first-line treatment, even in patients with psychiatric comorbidity. However, more controlled studies are required, particularly to determine continuous positive airway pressure compliance in patients with mental illness, the impact of treating OSA on psychiatric symptoms, and the impact of the use of psychotropic medications on OSA symptoms.
\end{abstract}

Keywords: obstructive sleep apnea, psychiatric disorders, comorbidity, psychotropic medications

\section{Background}

Obstructive sleep apnea (OSA) is a clinical syndrome in which a person recurrently stops breathing throughout his or her sleep. ${ }^{1}$ These interruptions in breathing are caused by an upper airway obstruction as a consequence of inadequate motor tone of the tongue and/or airway dilator muscles. Patients may experience partial (hypopnea) or complete (apnea) occlusion of airflow. With each period of apnea that the patient experiences, a reduction in blood oxygen levels (hypoxia) occur, causing arousals and fragmented sleep. Common symptoms include daytime sleepiness, fatigue, irritability and impaired cognitive function which have been linked to an increased risk of motor vehicle collisions and work-related injuries. ${ }^{2,3}$ Furthermore, sleep apnea is associated with serious health conditions including obesity, cardiovascular disorders such as hypertension, ischemic heart disease, arrhythmia, and heart failure; cerebrovascular disease; and endocrine disorders including the metabolic syndrome..$^{4-7}$

In addition to the serious health conditions previously described, psychiatric disorders and OSA are also frequently comorbid, especially with depression. ${ }^{8}$ It has been suggested that the mood disturbance may represent a consequence of sleep apnea; but it is also argued that psychiatric disorders and their pharmacological treatment may contribute to and promote the development of sleep apneas. ${ }^{9}$ Medications with inhibitory effects on the central nervous system (CNS) such as benzodiazepine receptor agonists, barbiturates, antiepileptic drugs, sedating antidepressants, antihistamines,
Correspondence: Monica Zolezzi

College of Pharmacy, Qatar University,

PO Box 27I3, Doha, Qatar

Tel +97444035623

Fax+974 4403555

Email mzolezzi@qu.edu.qa 
and opiates, all of which are commonly used in patients with psychiatric disorders, may also have an impact on sleep quality and architecture, and thus can worsen or further exacerbate the symptoms of OSA. ${ }^{10,11}$

However, there is currently a paucity of data evaluating the impact of psychotropic medications on OSA symptoms, on how to manage psychiatric pharmacotherapy in patients presenting with OSA, or on the effectiveness and challenges of OSA treatments in patients with comorbid mental illness. As such, the objective of this article is to provide an overview of some epidemiological aspects of OSA and treatment considerations in the management of OSA in individuals with comorbid psychiatric disorders.

\section{Methods}

A literature search on PubMed, Medline, Embase, Cochrane Database, and International Pharmaceutical Abstracts was conducted for relevant English-language articles from 1980 to June 2015. The main search keywords included the following: ["therapy" OR "treatment" OR "therapeutics"] AND ["sleep apnea" OR "obstructive sleep apnea"] AND ["psychiatry" OR "psychiatric patients" OR “psychiatric disorders”], and ["mental health" OR "mental health patients" OR "mental health disorders"]. The search was restricted to review publications in the adult patient population. Additional articles in relation to the treatment of OSA in the psychiatric population were obtained by manually searching the guidelines, the bibliography of retrieved review articles, and the position papers of relevant national or international association Web sites. A total of 80 articles were selected for this review.

\section{Risk factors, screening, and diagnosis of OSA}

The prevalence of OSA is higher in patients who have a combination of the following risk factors: obesity, neck larger than 17 inches for men or 16 inches for women, male sex, age $\geq 40$ years, large tonsils, or recessed chin. ${ }^{12}$ Differences in the structure and physiological behavior of the upper airway, in craniofacial morphology, and in the pattern of fat deposition between the sexes have been proposed to account for a higher male risk of OSA. ${ }^{13-15}$ It is imperative that at-risk patients be screened and appropriately treated to prevent complications, as untreated OSA is currently recognized as an independent risk factor for mortality. ${ }^{1}$

Patients who present with or describe signs and symptoms of choking or gasping during sleep, repeated awakenings from sleep, unrefreshing sleep, daytime fatigue, and impaired concentration should be suspected of having OSA. While men often report symptoms such as snoring, waking up gasping for air or snorting, many women report symptoms like fatigue, anxiety, and depression. ${ }^{15}$

Because the clinical features are nonspecific and the diagnostic accuracy of clinical impression alone is poor, a variety of clinical questionnaires and scores have been developed to assess patients with common signs and symptoms of OSA. The Epworth Sleepiness Scale (ESS), which is used to subjectively assess pretreatment sleepiness, is a selfadministered questionnaire that consists of eight scenarios, wherein patients rate whether there is a high chance of their dozing or falling asleep in that particular situation. ${ }^{16}$ Another validated tool to screen patients for OSA is the STOP and the STOP-BANG questionnaires (the latter having a higher sensitivity). ${ }^{17}$ STOP-Bang involves questions pertaining to Snoring, Tiredness, Observed apnea, blood Pressure, Body mass index, Age, Neck circumference, and Sex.

Depending on level of urgency, which is ranked by suspicion of OSA, the screening score, the individual's occupation, and the presence of comorbidities, most recent guidelines recommend polysomnography (PSG) for diagnostic testing. ${ }^{14,18,19}$ The diagnosis of OSA is based on the presence or absence of related symptoms, as well as the frequency of respiratory events during sleep (ie, apneas, hypopneas, and respiratory-effort-related arousals) as measured by a standardized facility-based PSG. The primary outcome measure of PSG is the apnea-hypopnea index (AHI), which is the average number of disordered breathing events per hour. Typically, OSA is defined as an AHI of 5 or greater with associated symptoms (eg, excessive daytime sleepiness, fatigue, or impaired cognition) or an AHI of 15 or greater, with or without associated symptoms..$^{1,14,20}$

\section{Management of OSA}

Guidelines for the management of OSA recommend continuous positive airway pressure (CPAP) as the first treatment of choice. ${ }^{20-22}$ A CPAP machine provides a constant flow of air at a pressure that maintains an open upper airway via a mask on either the mouth and/or nose. ${ }^{1,14}$ When compared with controls, CPAP use in patients with moderate and severe OSA has shown significant improvements in sleepiness, quality of life, cognitive function, and 24-hour blood pressures. ${ }^{23}$ Despite its well-recognized benefits, CPAP acceptance and adherence remain problematic. ${ }^{1,14,24}$ Education and support for patients who are experiencing difficulties have been reported to respond favorably and improve adherence. . $14,24^{-}$

Other alternative nonpharmacological treatments are oral appliances, weight loss, and surgery. ${ }^{25,26}$ Oral appliances are 
an alternative for patients with mild-to-moderate OSA who are unable to tolerate CPAP therapy. ${ }^{1,14}$ Appliances exhibit their effect by causing displacement of the mandible, which expands the diameter of the upper airways. ${ }^{23}$ Common to all guidelines is the recommendation that weight loss should be encouraged in all obese patients diagnosed with OSA. ${ }^{21,22,26}$ It is important, however, that attempts to lose weight should not delay the initiation of CPAP when indicated. ${ }^{21}$ Surgery may also be an option for some OSA patients. The type of surgery required varies depending on which particular part of the patient's airway is blocked. ${ }^{25}$

A number of pharmacological agents have been investigated for the treatment of OSA. ${ }^{27}$ However, most guidelines do not recommend pharmacological agents as first-line therapies for OSA. ${ }^{21,22}$ Nonetheless, the guidelines and a few reports also highlight that relief of nasal obstruction and agents that promote wakefulness may be useful adjuncts in the treatment of patients with OSA to either facilitate treatment with CPAP or help decrease daytime sleepiness despite other therapies. ${ }^{14,21,22,28}$

\section{Comorbidity of OSA in patients with mental illness}

Overall, the evidence is stronger and is rapidly building for an association of OSA with depression and anxiety. In a large cohort study of patients with sleep apnea, psychiatric comorbidity included depression $(21.8 \%)$, anxiety (16.7\%), posttraumatic stress disorder (PTSD) (11.9\%), psychosis (5.1\%), and bipolar disorders $(3.3 \%) .{ }^{9}$ A recently published systematic review indicated that there may be an increased prevalence of OSA in individuals with major depressive disorder and with PTSD. ${ }^{29}$ Another recent retrospective study found that there is a significant increased likelihood of being diagnosed with OSA and a mood disorder (odds ratio $[\mathrm{OR}]=1.85$; 95\% confidence interval $[\mathrm{CI}]=1.71-1.72$ ) or an anxiety disorder $(\mathrm{OR}$ $=1.82 ; 95 \% \mathrm{CI}=1.77-1.84) .{ }^{8}$ Notably, this positive relation remained after accounting for severity of body mass index. Other authors have also reported positive correlations between anxiety and depression in patients with OSA. ${ }^{30-34}$

In a systematic review of the literature, Youssef et al indicated that the prevalence of OSA in patients with attention deficit hyperactivity disorder (ADHD) is higher than in the general population, approximately $25 \%-30 \%$ versus $3 \%$, respectively. ${ }^{35}$ In another more recent study, although ADHD was not a frequent illness in adult patients with OSA, those with OSA and ADHD showed higher levels of anxiety and daytime sleepiness and poorer quality of life than in those without ADHD. ${ }^{36}$ Although OSA and insomnia appear to be opposing conditions based on the indicators of alertness and sleepiness, as pointed out by Luyster et al, ${ }^{37}$ numerous studies have found that these two conditions frequently coexist, with $39 \%-54.9 \%$ of patients with OSA either meeting criteria for insomnia or displaying insomnia symptoms as defined by the individual studies. ${ }^{37}$

There seems to be insufficient evidence to support increased OSA in schizophrenia or in bipolar disorder; ${ }^{29}$ however, individuals with these conditions are known to be at an increased risk for metabolic syndrome and obesity, which are also important risk factors for OSA. ${ }^{38-40}$ Although a causal relationship between OSA and Alzheimer's disease (AD) has not been established, in a recent review of the literature, authors indicated that the sleep fragmentation and intermittent hypoxia that occurs in OSA could promote cognitive dysfunction, overlapping with that in $\mathrm{AD}$ and other neurodegenerative diseases. ${ }^{41}$

\section{Psychotropic medications and the management of OSA \\ Antipsychotics}

OSA is often overlooked in the context of schizophrenia, because its hallmark symptom, daytime sleepiness, is so easily attributable to antipsychotic medications. ${ }^{38}$ The use of atypical antipsychotics is associated with a near doubling of the risk of severe OSA, possibly due to an induction of abnormal upper airway tone or alteration in respiratory control secondary to dopamine receptor antagonism. ${ }^{42}$ As obesity is one of the main precipitating factors of OSA, medication-induced weight gain, a well-known side effect from atypical antipsychotics, can lead to worsening or exacerbating OSA symptoms. ${ }^{38}$ Interestingly, Shirani et al found that the use of atypical antipsychotics in subjects with depression, but not in those with other psychiatric diagnoses, appeared to increase the risk of OSA after controlling for known predisposing factors. ${ }^{43}$

\section{Antidepressants}

Various types of antidepressants have been investigated for the treatment of OSA, and, as depression has been linked with OSA, treatment with a tricyclic antidepressant (TCA), selective serotonin receptor inhibitor (SSRI), or another form of serotonergic agent may provide benefits for both of these diseases. The use of TCAs has been reported to result in an approximately $10 \%$ decrease in rapid eye movement (REM) sleep. ${ }^{10}$ As apneas tend to more frequently occur in REM sleep, a decrease in this stage provides a protective mechanism against respiratory-related arousals. ${ }^{10,44}$ However, clinical consequences of REM suppression can be a change in frequency and intensity of dreaming, as well as a possible 
negative effect on memory and learning. ${ }^{44}$ Protriptyline has been the most studied TCA in OSA patients. Three crossover studies published in the 1980s comparing protriptyline to placebo demonstrated a nonsignificant improvement in objective apnea parameters or symptoms..$^{45-47}$

It has been reported that the levels of serotonin are reduced in patients with depression and in certain sleep states that can cause augmentation of OSA symptoms. ${ }^{10}$ In the management of OSA, SSRIs have been advocated to produce a reduction in REM sleep as well as improving upper airway dilator tone through an increase in serotonin levels. ${ }^{10,48}$ When compared with protriptyline, fluoxetine significantly reduced REM sleep and significantly improved the AHI score during non-REM sleep. ${ }^{48}$ However, there were no significant improvements in AHI during REM sleep, or in oxygen desaturations and arousals. In another placebo crossover trial involving 20 patients, paroxetine 20 mg taken orally once daily for 6 weeks reduced AHI during non-REM sleep $(-35 \%, P=0.003)$ but showed no significant effects on psychopathologic- or OSA-related daytime symptoms. ${ }^{49}$ Interestingly, in another study in patients with coronary artery disease, the use of sertraline was ineffective in managing depression in patients with OSA. ${ }^{50}$ However, the effects of sertraline on the symptoms of OSA were not assessed in this study.

On the basis of these findings that endogenous serotonin release in the brainstem promotes upper airway dilation during the awake state while peripheral serotonin release at $5-\mathrm{HT}_{3}$ receptors promotes REM-related apnea, Prasad et al tested if using an SSRI (fluoxetine) in combination with a medication that inhibits $5-\mathrm{HT}_{3}$ receptors (ondansetron) would be advantageous. ${ }^{51}$ However, patients treated with the combination did not report significant improvement in OSArelated symptoms versus those on placebo. In another study, Carley et al investigated whether mirtazapine, a mixed 5 $\mathrm{HT}_{2}$ and $5 \mathrm{HT}_{3}$ antagonist, would have beneficial effects for OSA patients. ${ }^{52}$ After 1 week of treatment, the mean AHI decreased from 22.3 for placebo treatment to 13.5 and 11.4 per hour for 4.5 and $15 \mathrm{mg}$ doses, respectively $(P<0.004)$. In addition, sleep efficiency and REM sleep percentage were significantly increased by the $15 \mathrm{mg}$ per day dose $(P=0.04)$. Marshall et al further researched the use of mirtazapine in OSA by reporting on two separate randomized, double-blind, placebo-controlled trials. ${ }^{53}$ Across both studies, there was no significant difference in the amount of time spent asleep or in AHI. Additionally, there was a significant increase in weight in patients taking mirtazapine across all treatment groups in both studies, which may worsen OSA.

\section{Sedative/hypnotics}

Benzodiazepines and other sedatives or hypnotics may be used for insomnia or anxiety in patients with diverse psychiatric conditions. The use of benzodiazepines in patients with OSA has been limited because of their known risk of causing reduced upper airway muscle tone and decreased ventilatory response to hypoxia, thus potentially increasing the AHI and prolonging apnea events. ${ }^{36,54}$ If an airway obstruction occurs, ventilation is resumed in response to CNS arousal that allows the patient to awaken to voluntarily dilate the airway. The more sedated the patient is, the more difficult it is to rouse and consequently the longer it takes to reopen the airway.

Nonbenzodiazepine agents, such as zopiclone, zolpidem, and eszopiclone, have hypnotic and sedative effects similar to those of benzodiazepines, but some have fewer musclerelaxant effects; thus, they may be preferable to use in the short-term management of insomnia in OSA. ${ }^{11,36}$ Studies have documented that the use of zolpidem in doses up to $10 \mathrm{mg}$ did not impede the use of CPAP in patients with severe OSA; however, there was a reduction in sleep latency and mean arousal index. ${ }^{55}$ For this, benzodiazepines and any medication that may cause sedation, including opioids or sleeping aids, should be used with caution in patients with OSA and should be closely monitored, particularly when titrating doses. ${ }^{11}$ The short-term use of nonbenzodiazepine agents has been advocated through various studies as a safe and effective strategy for improving compliance with CPAP in patients with comorbid psychiatric disorders. ${ }^{5-57}$

\section{Stimulants}

Psychostimulant medications are associated not only with disrupted or disturbed sleep, but also, paradoxically, calm some patients with ADHD to sleep by alleviating their symptoms. ${ }^{58}$

Studies using modafinil, a nonamphetamine stimulant medication used in the treatment of ADHD, have shown significant reduction of excessive daytime sleepiness associated with OSA in both objective and subjective measures with this medication. ${ }^{59,60}$ In most guidelines, modafinil is recommended for use in patients who have residual daytime sleepiness despite optimal use of CPAP..$^{20-22,26,28,61}$

Despite the aforementioned benefits of modafinil as adjunct therapy, its use is associated with some risks, including cardiovascular complications, dependency, and abuse potential. Heitmann et al studied blood pressure effects of modafinil in patients with OSA. ${ }^{62}$ The effect on blood pressure was not significant between modafinil and placebo, but 
as this study occurred over a very short period of time, the long-term cardiovascular implications require further investigation. Because of the greater risk of dependency and abuse with stimulant medications, they are not recommended for the treatment of OSA at this time..$^{20-22}$

\section{Miscellaneous}

As rates of smoking are at least two times higher among patients with psychiatric disorders, ${ }^{63}$ the value of nicotine replacement products for patients with both psychiatric disorders and OSA was also researched. Nicotine may improve OSA by stimulating respiration and oropharyngeal muscles. ${ }^{64}$ A small study of eight patients by Gothe et al found that the use of 2 and $4 \mathrm{mg}$ nicotine gum significantly reduced the number of apneas, during both the first and second hour of sleep. ${ }^{65}$ However, studies looking at other forms of nicotine administration, such as transdermal patch, did not show any effect on AHI ${ }^{66}$ As nicotine acts as a stimulant, it has been reported that sleep efficiency and sleep architecture are negatively affected in these studies. ${ }^{63,67}$ Therefore, although smoking cessation should be promoted and encouraged among patients with mental illness, the use of nicotine strictly for the treatment of OSA has not been reported to offer clear benefits.

Of particular importance is the avoidance, or reduction, of alcohol intake. Ingestion of alcohol before sleep has been shown to increase upper airway collapsibility, therefore, precipitating obstructive apneas and hypopneas during sleep. ${ }^{67}$ The severity of the effects of alcohol on OSA is controversial, likely due to the variation in amounts that patients may consume prior to sleep. Peppard et al found that relative to men who drank less alcohol, for each increment of one drink per day, there was a $25 \%$ greater odds of worsened episodes of sleep apnea $(P=0.006) .{ }^{68}$ For this reason, avoidance (or moderation if avoidance is not possible) of alcohol should be encouraged for patients diagnosed with OSA.

\section{CPAP for the management of OSA in patients with mental illness}

No controlled studies have exclusively focused on the use of CPAP in patients with severe mental illness; however, there are case reports describing improvement in both OSA and psychiatric symptoms with the use of CPAP in patients with schizophrenia. ${ }^{69-71}$

Unlike in schizophrenia and bipolar disorder, the use of CPAP in patients with comorbid depression and/or anxiety disorders has been extensively studied. El-Sherbini et al found a significant reduction in depressive symptoms as determined by the Hamilton Depression Rating Scale and improvement in ESS scores (11.6 \pm 8.6 to 5.1 \pm 3.1 ) after CPAP treatment for 2 months. ${ }^{72}$ In a recent systematic review of the literature and meta-analysis, Povitz et al reported that CPAP improved depressive symptoms compared to the control intervention (usually sham CPAP) but revealed considerable variability between trials. ${ }^{73}$ Notably, CPAP treatment resulted in a greater improvement in depressive symptoms in trials in which there was a high prevalence of depression at baseline than in trials in which there was a low prevalence of depression at baseline. CPAP has also been reported to be effective in OSA patients with comorbid PTSD, showing reduction in PTSD-associated nightmares and improving the overall PTSD symptoms. ${ }^{74}$ Similarly, when it was used in patients with panic disorder, CPAP showed positive outcomes in the severity and the frequency of panic attacks. ${ }^{56}$ Likewise, in patients with ADHD, Youssef et al investigated the effects of CPAP treatment on ADHD and established that in six interventional studies, either improvement or resolution of ADHD occurred after treatment with CPAP or surgery. ${ }^{34}$

Krakow et al examined the effect of CPAP, oral appliances, or surgery on sleep measures in patients with chronic insomnia and episodes of sleep apnea who completed a cognitive behavior therapy program. ${ }^{55}$ Both treatment phases (cognitive behavior therapy alone or in combination with OSA treatment of CPAP, oral appliance, or surgery) resulted in improvements in insomnia severity and sleep-related daytime impairments; however, cognitive behavior therapy alone had a small effect on daytime impairments.

The current literature review also revealed only a few case reports of CPAP-induced psychiatric relapse, one in a previously stable chronic schizophrenic as well as emergent manic episodes in patients with bipolar disorder. ${ }^{75,76}$ As previously discussed, compliance with CPAP is challenging; however, this has not been extensively evaluated in patients with psychiatric disorders. ${ }^{29}$ Some studies have demonstrated adequate CPAP compliance in patients with PTSD and AD. ${ }^{77,78}$ Some studies have also reported on the negative influence of the presence of depression during the CPAP titration trial and on the presence of untreated insomnia symptoms on CPAP compliance. ${ }^{79,80}$ However, further studies are needed to clarify whether the treatment of depression and insomnia symptoms leads to a benefit in CPAP compliance.

\section{Conclusion}

OSA is particularly prevalent in patients with psychiatric disorders. The medical care that patients with these comorbidities require can be challenging as some of the psychiatric medications used by these patients may worsen 
or exacerbate OSA symptoms. Although pharmacotherapy for the management of OSA is available, evidence on their efficacy is not robust. As such, CPAP continues to be the firstline treatment, even in patients with psychiatric comorbidity. However, more controlled studies are required, particularly to determine CPAP compliance in patients with mental illness, the impact of treating OSA on psychiatric symptoms, and the impact of the use of psychotropic medications on OSA symptoms.

\section{Disclosure}

The authors report no conflicts of interests in this work.

\section{References}

1. Park JG, Ramar K, Olson EJ. Updates on definition, consequences, and management of obstructive sleep apnea: concise review for clinicians. Mayo Clin Proc. 2011;86(6):549-555.

2. Yaffe K, Laffan AM, Harrison SL, et al. Sleep-disordered breathing, hypoxia, and risk of mild cognitive impairment and dementia in older women. JAMA. 2011;306:613.

3. Tregear S, Reston J, Schoelles K, Phillips B. Obstructive sleep apnea and risk of motor vehicle crash: systematic review and meta-analysis. J Clin Sleep Med. 2009;5:573-581.

4. Phillips CL, O’Driscoll DM. Hypertension and obstructive sleep apnea. Nat Sci Sleep. 2013;5:43-52.

5. Somers VK, White DP, Amin R, et al. Sleep apnea and cardiovascular disease. Circulation. 2008;118:1080-1111.

6. Dong JY, Zhang YH, Qin LQ. Obstructive sleep apnea and cardiovascular risk: meta-analysis of prospective cohort studies. Atherosclerosis. 2013;229(2):489-495.

7. Fredheim JM, Rollheim J, Omland T, et al. Type 2 diabetes and pre-diabetes are associated with obstructive sleep apnea in extremely obese subjects: a cross-sectional study. Cardiovasc Diabetol. 2011; 10:84.

8. Babson KA, Del Re AC, Bonn-Miller MO, Woodward SH. The comorbidity of sleep apnea and mood, anxiety, and substance use disorders among obese military veterans within the veterans health administration. $J$ Clin Sleep Med. 2013;9(12):1253-1258.

9. Sharafkhaneh A, Giray N, Richardson P, Young T, Hirshkowitz M. Association of psychiatric disorders and sleep apnea in a large cohort. Sleep. 2005;28(11):1405-1411.

10. Smith SS, Dingwall K, Jorgenson G, Douglas J. Associations between the use of common medications and sleep architecture in patients with untreated obstructive sleep apnea. J Clin Sleep Med. 2006;2(2):156-162.

11. Anonymous. Medications that can exacerbate sleep apnea. Pharmacist's Letter/Prescriber's Letter. 2008;24(10):241007.

12. Young T, Skatrud J, Peppard PE. Risk factors for obstructive sleep apnea in adults. JAMA. 2004;291:2013.

13. Quintana-Gallegoa E, Carmona-Bernala C, Capotea F, et al. Gender differences in obstructive sleep apnea syndrome: a clinical study of 1,166 patients. Resp Med. 2004;98:984-989.

14. Jordan AS, McSharry DG, Malhotra A. Adult obstructive sleep apnoea. Lancet. 2014;383(9918):736-747.

15. Sforza E, Chouchou F, Collet P, Pichot V, Barthelemy JC, Roche F. Sex differences in obstructive sleep apnoea in an elderly French population. Eur Respir J. 2011;37:1137-1143.

16. Johns MW. A new method for measuring daytime sleepiness: the Epworth sleepiness scale. Sleep. 1991;14(6):540-545.

17. Chung F, Yegneswaran B, Liao P, et al. STOP questionnaire: a tool to screen patients for obstructive sleep apnea. Anesthesiology. 2008;108: 812 .
18. Fleetham J, Ayas N, Bradley D, et al. The Canadian Thoracic Society Sleep Disordered Breathing Committee. Canadian Thoracic Society 2011 guideline update: diagnosis and treatment of sleep disordered breathing. Can Respir J. 2011;18(1):25-47.

19. Qaseem A, Dallas P, Owens DK, et al. Diagnosis of obstructive sleep apnea in adults: a clinical practice guideline from the American College of Physicians. Ann Intern Med. 2014;161:210-220.

20. Epstein LJ, Kristo D, Strollo PJ Jr, et al. Adult Obstructive Sleep Apnea Task Force of the American Academy of Sleep Medicine. Clinical guideline for the evaluation, management and long-term care of obstructive sleep apnea in adults. J Clin Sleep Med. 2009;5:263-276.

21. Fleetham J, Ayas N, Bradley D, et al. Canadian Thoracic Society guidelines: diagnosis and treatment of sleep disordered breathing in adults. Can Respir J. 2006;13(7):387-392.

22. Qaseem A, Dallas P, Owens DK, et al. Management of obstructive sleep apnea in adults: a clinical practice guideline from the American College of Physicians. Ann Intern Med. 2013;159:471-483.

23. Giles TL, Lasserson TJ, Smith B, White J, Wright JJ, Cates CJ. Continuous positive airways pressure for obstructive sleep apnoea in adults. Cochrane Database Syst Rev. 2006;3:1-103.

24. Randerath WJ, Verbraecken J, Andreas S, et al. Non-CPAP therapies in obstructive sleep apnoea. Eur Respir J. 2011;37:1000-1028.

25. Weaver TE, Grunstein RR. Adherence to continuous positive airway pressure therapy. The challenge to effective therapy. Proc Am Thorac Soc. 2008;5(2):173-178.

26. Morgenthaler TI, Kapen S, Lee-Chiong T, et al. Practice parameters for the medical therapy of obstructive sleep apnea. Sleep. 2006;29: 1031-1035.

27. Lin CM, Huang YS, Guilleminault C. Pharmacotherapy of obstructive sleep apnea. Expert Opin Pharmacother. 2012;13(6):841-857.

28. Sukhal S, Khalid M, Tulaimat A. Effect of wakefulness-promoting agents on sleepiness in patients with sleep apnea treated with CPAP: A meta-analysis. J Clin Sleep Med. 2015; Epub March 27, 2015.

29. Gupta MA, Simpson FC. Obstructive sleep apnea and psychiatric disorders: a systematic review. J Clin Sleep Med. 2015;11(2):165-175.

30. Rezaeitalab F, Moharrari F, Saberi S, Asadpour H, Rezaeetalab F. The correlation of anxiety and depression with obstructive sleep apnea syndrome. J Res Med Sci. 2014;19(3):205-210.

31. Hayley AC, Williams LJ, Berk M, Kennedy GA, Jacka FN, Pasco JA. The relationship between excessive daytime sleepiness and depressive and anxiety disorders in women. Aust N Z J Psychiatry. 2013;47(8): $772-778$.

32. Hayley AC, Williams LJ, Venugopal K, Kennedy GA, Berk M, Pasco JA. The relationships between insomnia, sleep apnoea and depression: findings from the American National Health and Nutrition Examination Survey, 2005-2008. Aust N Z J Psychiatry. 2015;49(2):156-170.

33. Bajpai S, Im KB, Dyken ME, Sodhi SK, Fiedorowicz JG. Obstructive sleep apnea and risk for late-life depression. Ann Clin Psychiatry. 2014;26(3):163-170.

34. Ejaz SM, Khawaja IS, Bhatia S, Hurwitz TD. Obstructive sleep apnea and depression: a review. Innov Clin Neurosci. 2011;8(8):17-25.

35. Youssef NA, Ege M, Angly SS, Strauss JL, Marx CE. Is obstructive sleep apnea associated with ADHD? Ann Clin Psychiatry. 2011;23:213-224.

36. Oğuztürk Ö, Ekici M, Çimen D, Ekici A, Senturk E. Attention deficit/ hyperactivity disorder in adults with sleep apnea. J Clin Psychol Med Settings. 2013;20(2):234-239.

37. Luyster FS, Buysse DJ, Strollo PJ. Comorbid insomnia and obstructive sleep apnea: challenges for clinical practice and research. J Clin Sleep Med. 2010;6(2):196-204.

38. Lin WC, Winkelman JW. Obstructive sleep apnea and severe mental illness: evolution and consequences. Curr Psychiatry Rep. 2012;14(5): 503-510.

39. Alam A, Chengappa KN, Ghinassi F. Screening for obstructive sleep apnea among individuals with severe mental illness at a primary care clinic. Gen Hosp Psychiatry. 2012;34(6):660-664.

40. Winkelman JW. Schizophrenia, obesity, and obstructive sleep apnea. J Clin Psychiatry. 2001;62:8-11. 
41. Pana W, Kastina AJ. Can sleep apnea cause Alzheimer's disease? Neurosci Biobehav Rev. 2014;47:656-669.

42. Rishi MA, Shetty M, Wolff A, Amoateng-Adjegpong Y, Manthous CA. Atypical antipsychotic medications are independently associated with severe obstructive sleep apnea. Clin Neuropharmacol. 2010;194: 491-499.

43. Shirani A, Paradiso S, Dyken ME. The impact of atypical antipsychotic use on obstructive sleep apnea: a pilot study and literature review. Sleep Med. 2011;12(6):591-597.

44. DeMartinis NA, Winokur A. Effects of psychiatric medications on sleep and sleep disorders. CNS Neurol Disord Drug Targets. 2007;6: 17-29.

45. Brownell L, West P, Sweatmen P, Acres J, Kryger M. Protriptyline in obstructive sleep apnoea: a double blind trial. NEngl JMed. 1982;307(17): 1037-1042.

46. Stepanski E, Conway W, Young D, Zorick F, Wittig R, Roth T. A doubleblind trial of protriptyline in the treatment of sleep apnoea syndrome. Henry Ford Hosp Med J. 1988;36(1):5-8.

47. Whyte K, Gould G, Airlie A, Shapiro G, Douglas N. Role of protriptyline and acetazolomide in the sleep apnea/hypopnea syndrome. Sleep. 1988;11(5):463-472.

48. Kraiczi H, Hedner J, Dahlof, Ejnell H, Carlson J. Effect of serotonin uptake inhibition on breathing during sleep and daytime symptoms in obstructive sleep apnea. Sleep. 1999;22(1):61-67.

49. Hanzel DA, Proia NG, Hudgel DW. Response of obstructive sleep apnea to fluoxetine and protriptyline. Chest. 1991;100:416-421.

50. Roest AM, Carney RM, Stein PK, et al. Obstructive sleep apnea/ hypopnea syndrome and poor response to sertraline in patients with coronary heart disease. J Clin Psychiatry. 2012;73(1):31-36.

51. Prasad B, Radulovacki M, Olopade C, Herdegen JJ, Logan T, Carley DW. Prospective trial of efficacy and safety of ondansetron and fluoxetine in patients with obstructive sleep apnea syndrome. Sleep. 2010;33(7): 982-989.

52. Carley DW, Olopade C, Ruigt GS, Radulovacki M. Efficacy of mirtazapine in obstructive sleep apnea syndrome. Sleep. 2007;30(1):35-41.

53. Marshall NS, Yee BJ, Desai AV, et al. Two randomized placebo-controlled trials to evaluate the efficacy and tolerability of mirtazapine for the treatment of obstructive sleep apnea. Sleep. 2008;31(6):824-831.

54. Sharafkhaneh A, Hirshkowitz M. The correlation between sleep-disordered breathing and psychiatry. Psychiatr Times. Available at: http://www.psychiatrictimes.com/sleep-disorders/correlationbetween-sleep-disordered-breathing-and-psychiatry. Published July 9 , 2012. Accessed June 15, 2015.

55. Krakow B, Melendrez D, Lee SA, Warner TD, Clark JO, Sklar D. Refractory insomnia and sleep-disordered breathing: a pilot study. Sleep Breath. 2004;8:15-29.

56. Takaesu Y, Inoue Y, Komada Y, Kagimura T, Iimori M. Effects of nasal continuous positive airway pressure on panic disorder comorbid with obstructive sleep apnea syndrome. Sleep Med. 2012;13(2):156-160.

57. Lettieri CJ, Shah AA, Holley AB, Kelly WF, Chang AS, Roop SA Effects of a short course of eszopiclone on continuous positive airway pressure adherence. Ann Intern Med. 2009;151:696-702.

58. Hvolby A. Associations of sleep disturbance with ADHD: implications for treatment. Atten Defic Hyperact Disord. 2015;7(1):1-18.

59. Bittencourt LR, Lucchesi LM, Rueda AD, et al. Placebo and modafinil effect on sleepiness in obstructive sleep apnea. Prog Neuropsychopharmacol Biol Psychiatry. 2008;32:552-559.

60. Chapman JL, Kempler L, Chang CL, et al. Modafinil improves daytime sleepiness in patients with mild to moderate obstructive sleep apnoea not using standard treatments. Thorax. 2014;69(3):274-279.

61. Veasey SC, Guilleminault C, Strohl KP, Sanders MH, Ballard RD, Magalang UJ. Medical therapy for obstructive sleep apnea: a review by the Medical Therapy for Obstructive Sleep Apnea Task Force of the Standards of Practice Committee of the American Academy of Sleep Medicine. Sleep. 2006;29(8):1036-1044.
62. Heitmann J, Cassel W, Grote L, et al. Does short-term treatment with modafinil affect blood pressure in patients with obstructive sleep apnea. N Engl J Med. 1996;334:9-104.

63. Kalman D, Morissette SB, George TP. Co-morbidity of smoking in patients with psychiatric and substance use disorders. Am J Addict. 2005;14(2):106-123.

64. Zevin S, Swed E, Caban C. Clinical effects of locally delivered nicotine in obstructive sleep apnea syndrome. Am J Ther. 2003;10(3):170-175.

65. Gothe B, Strohl KP, Levin S, Cherniack NS. Nicotine: a different approach to treatment of obstructive sleep apnea. Chest. 1985;87(1):11-17.

66. Davila DG, Hurt RD, Offord KP, Harris CD, Shepard JW. Acute effects of transdermal nicotine on sleep architecture, snoring, and sleep-disordered breathing in nonsmokers. Am J Respir Crit Care Med. 1994;150: 469-474.

67. Issa FG, Sullivan CE. Alcohol, snoring and sleep apnea. J Neurol Neurosurg Psychiatry. 1982;45:353-359.

68. Peppard PE, Austin D, Brown RL. Association of alcohol consumption and sleep disordered breathing in men and women. J Clin Sleep Med. 2007;3:265-270.

69. Kalucy MJ, Grunstein R, Lambert T, Glozier N. Obstructive sleep apnoea and schizophrenia. A research agenda. Sleep Med Rev. 2013;17(5): $357-365$.

70. Seeman MV. Diagnosis and treatment of sleep apnoea in women with schizophrenia. J Men Health. 2014;23(4):191-196.

71. Boufdis S, Kosmidis MH, Bozikas VP, Daskalopoulou-Vlahoyianni E, Pitsavas S, Karavatos A. Treatment outcome of obstructive sleep apnea syndrome in a patient with schizophrenia: case report. Int J Psychiatry Med. 2003;33(3):305-310.

72. El-Sherbini AM, Bediwy AS, El-Mitwalli AE. Association between obstructive sleep apnea and depression and the effect of continuous positive airway pressure treatment. Neuropsychiatr Dis Treat. 2011;7: $715-721$.

73. Povitz M, Bolo CE, Heitman SJ, Tsai WH, Wang J, James MT. Effect of treatment of obstructive sleep apnea on depressive symptoms: systematic review and meta-analysis. PLoS Med. 2014;11(11):e1001762.

74. Tamanna S, Parker JD, Lyons J, Ullah MI. The effect of continuous positive air pressure (CPAP) on nightmares in patients with posttraumatic stress disorder (PTSD) and obstructive sleep apnea (OSA). J Clin Sleep Med. 2014;10(6):631-636.

75. Chiner E, Arriero JM, Signes-Costa J, Marco J. Acute psychosis after CPAP treatment in a schizophrenic patient with sleep apnoeaehypopnoea syndrome. Eur Respir J. 2001;17:313e5.

76. Aggarwal R, Baweja R, Saunders EF, Singareddy R. CPAP-induced mania in bipolar disorder: a case report. Bipolar Disord. 2013;15(7):803-807.

77. Ayalon L, Ancoli-Israel S, Stepnowsky C, Marler M, Palmer BW, Liu L, et al. Adherence to continuous positive airway pressure treatment in patients with Alzheimer's disease and obstructive sleep apnea. Am J Geriatr Psychiatry. 2006;14(2):176-180.

78. El-Solh AA, Ayyar L, Akinnusi M, Relia S, Akinnusi O. Positive airway pressure adherence in veterans with posttraumatic stress disorder. Sleep. 2010;33(11):1495-1500.

79. Law M, Naughton M, Ho S, Roebuck T, Dabscheck E. Depression may reduce adherence during CPAP titration trial. J Clin Sleep Med. 2014; 10(2):163-169.

80. Pieh C, Bach M, Popp R, et al. Insomnia symptoms influence CPAP compliance. Sleep Breath. 2013;17(1):99-104. 


\section{Publish your work in this journal}

Neuropsychiatric Disease and Treatment is an international, peerreviewed journal of clinical therapeutics and pharmacology focusing on concise rapid reporting of clinical or pre-clinical studies on a range of neuropsychiatric and neurological disorders. This journal is indexed on PubMed Central, the 'PsycINFO' database and CAS,

and is the official journal of The International Neuropsychiatric Association (INA). The manuscript management system is completely online and includes a very quick and fair peer-review system, which is all easy to use. Visit http://www.dovepress.com/testimonials.php to read real quotes from published authors.

Submit your manuscript here: http://www.dovepress.com/neuropsychiatric-disease-and-treatment-journal 